\title{
Profit Models Based on the Growth Dynamics of Lettuce Populations in a Plant Factory
}

\author{
Shogo Moriyuki ${ }^{1}$, Hiroaki KANEdA ${ }^{1}$, Yusaku MiYAGi ${ }^{1}$, Nobuhiro SugImURA ${ }^{1}$ and Hirokazu FukUdA ${ }^{1,2}$ \\ ${ }^{1}$ Graduate School of Engineering, Osaka Prefecture University, Sakai, Osaka 599-8531, Japan \\ ${ }^{2}$ Japan Science and Technology Agency, Precursory Research for Embryonic Science and Technology, Kawaguchi, \\ Saitama 332-0012, Japan
}

(Received July 2, 2018; Accepted August 16, 2018)

\begin{abstract}
A profit model provides a guideline for facility construction and management of plant factories. Practically, the model depends on plant growth conditions and shipping type in each plant factory and these parameters should be optimized. However, the profit model has not been studied well. In this study, we focused on plant growth dynamics and three shipping types. A mathematical model of growth dynamics describes the time change of average and distribution of fresh weight from nursing to harvesting. The parameters of the profit model were investigated based on experimental data in a commercial plant factory. In the experimental results, the yield was strongly dependent on the growth dynamics of the lettuce population. From the sensitivity analysis of each parameter, it was clarified that the quality of seedling and the cultivation days are mostly effective for profit as high priority parameters. Our results suggest that it is important to regulate the growth dynamics at early stages (young seedling stage) and cultivation days in order to maximize profit in plant factories.
\end{abstract}

Keywords : growth distribution, Lactuca sativa L., profit model, sensitivity analysis, shipping type

\section{INTRODUCTION}

Crop production is increasingly threatened by unusual weather, water shortages, and insufficient available land. In order to feed the world, protect the environment, improve health, and achieve economic growth, a new form of agricultural cultivation is required; indoor vertical farming, namely a plant factory system with artificial lighting, is expected to provide efficient production of food crops (Kozai et al., 2015). However, production in plant factories incurs several costs. Kozai (2007) and Ohyama (2015) previously studied the production costs; as the size of the plant factory increases, fixed costs increase, for example, large-scale air conditioning systems, automatic control systems for nutrient solutions (Son and Takakura, 1987; Ko et al., 2013) and high-throughput seedling diagnosis system (Moriyuki and Fukuda, 2016). Moreover, individual differences in plant growth (growth distribution) are also directly linked to profits. Therefore, a profit model is required to consider fixed costs, running costs, and growth distribution information in plant factories.

In the profit model for plant factory, we should focus on shipping type and growth distribution at each growth stage (nursing stage and cultivating stage). The shipping type usually depends on a shipping threshold based on fresh weight of harvested plant. Plants over this threshold are able to be sold at a standard (good) price, one by one (yen plant ${ }^{-1}$ ). On the other hand, plants less than this threshold are sold at a lower price, by unit of fresh weight (yen $\mathrm{g}^{-1}$ ). Therefore, profit depends on the distribution of plant size at harvest, particularly on the ratio of standard plants that are over the shipping threshold. Moreover, because profit often fluctuates with growth fluctuations, the profit model also requires detailed information of growth dynamics (distribution of plant size and its time variation). However, growth dynamics in plant factory and their influence on profit as a function of shipping threshold have not been widely studied.

Variables in the profit model included number of cultivation days, shipping threshold, cost-related parameters such as fixed costs and running costs, and growth-related parameters. Furthermore, parameters in the profit model depend on the plant factory. Therefore, total optimization for all parameters requires time and expense (Shuku and Nishimura, 2015); thus, it is also important to analyze the sensitivity of each parameter for profit and to identify the priority of these parameters.

In this study, we investigated the growth dynamics of lettuce populations cultivated in a large scale commercial plant factory and established a profit model with various shipping types. In addition, the sensitivity analysis of this profit model was performed for each parameter, and significant parameters for profit were clarified.

\section{MATERIALS AND METHODS}

\section{Growth dynamics}

The growth curve of plants is typically seen as a logistic curve (Soran and Lazar-Keul, 1978). In particular, the

Corresponding author: Shogo Moriyuki, fax +81-72-254-6376,

e-mail : sssmskztmissue@yahoo.co.jp 
average plant size is clearly described by a logistic curve as follows,

$$
\begin{aligned}
& \frac{d \mu}{d t}=K \mu\left(\mu_{\max }-\mu\right) \\
& \mu(t)=\frac{\mu_{\max }}{1+\exp \left[-K \mu_{\max }\left(t-t_{o}\right)\right]}\left(0<\mu(t)<\mu_{\max }\right)
\end{aligned}
$$

Here, $\mu(t)(\mathrm{g})$ is the average of fresh weight at the time $t$ (day) after sowing. $\mu_{\max }(\mathrm{g})$ is the maximum value at the time infinite, $K\left(g^{-1} \mathrm{~d}^{-1}\right)$ is the coefficient of growth rate, and $t_{o}$ (day) is the time at which $\mu(t)$ becomes $\mu_{\max } / 2$. $t_{o}$ also decides the plant size at the initial time $t=0\left(\mu_{0}=\right.$ $\left.\mu_{\max } /\left\{1+\exp \left[K \mu_{\max } t_{o}\right]\right\}\right)$.

In addition, we introduced the coefficient of variance $a(t)\left(\mathrm{g} \mathrm{g}^{-1}\right)$ of the fresh weight at each time as follows,

$$
a(t)=\frac{\sigma(t)}{\mu(t)}
$$

Here, $\sigma(t)(\mathrm{g})$ is the standard deviation of average of fresh weight. In this study, we calculated $t_{o}, \mu_{\max }, K$ and $a(t)$ using Generalized Reduced Gradient (GRG) method (Gabriele and Ragsdell, 1977) based on experimental data.

\section{Profit model of plant factory}

In order to establish the profit model for the plant factory, we focused on shipping types and growth dynamics. The profit $Y$ (yen $\mathrm{d}^{-1}$ ) was defined by both total sale $T_{s}$ (yen $\mathrm{d}^{-1}$ ) and total cost. Total cost involves the fixed costs and running costs. In a plant factory that reaches steady operations, the construction, employment and seed costs are defined as fixed costs. On the other hand, utility, electrical and water costs are defined as running costs. In a plant factory, cultivation processes can change according to growing stage, that is, the nursing and cultivating stage. Therefore, it is necessary to calculate these separately for the fixed and running costs. In the profit model of this study, we defined the number of days for nursing as a constant value $d$ (day), and we investigated how it affects profit by changing total cultivation time $t$ (day) after sowing. From this viewpoint, the profit model is described as follows:

$$
Y(t)=T_{s}-[\alpha+\mathrm{d} \beta+(t-d) \gamma] n S
$$

Where $\alpha(-), \beta\left(\mathrm{d}^{-1}\right)$, and $\gamma\left(\mathrm{d}^{-1}\right)$ are cost-related parameters for the fixed costs, the running costs at nursing room, and the running costs at cultivation room, respectively. $n$ (plant $\mathrm{d}^{-1}$ ) is the number of sown seeds every day. $S$ (yen plant $^{-1}$ ) is the standard price per lettuce head. In this study, we calculated the values of cost-related parameters and nursing days $d$ (Table 1).

The shipping type is usually defined by a shipping threshold $w^{*}(\mathrm{~g})$ on fresh weight of harvested plant. Plants over this threshold are able to be sold at a standard price $S$ (yen plant ${ }^{-1}$ ), one by one. On the other hand, plants less than this threshold are sold at a lower price, by unit of fresh weight $\left(\right.$ yen $\mathrm{g}^{-1}$ ). We defined standard price per fresh weight $s_{s}\left(\right.$ yen $\left.\mathrm{g}^{-1}\right)$ and low price per fresh weight $s_{l}$ (yen $\left.\mathrm{g}^{-1}\right)$, and category-weighting factor $\lambda(-)\left(=s_{l} / s_{s}\right)$. In a typical case, $\lambda=0.30$, that is, plants less than $w^{*}$ are sold at $70 \%$ lower price, $s_{s}$ and $s_{l}$ are described as follows:

$$
s_{s}=\frac{S}{w^{*}}, \quad s_{l}=\lambda \frac{S}{w^{*}}
$$

Table 1 Representative values for cost-related parameters $(\alpha, \beta, \gamma)$ and nursery days $d$ in plant factory. $\alpha(-), \beta\left(\mathrm{d}^{-1}\right)$, and $\gamma\left(\mathrm{d}^{-1}\right)$ are cost-related parameters for the fixed costs, the running costs at nursing room, and the running costs at cultivation room.

\begin{tabular}{cc}
\hline Parameter & Value \\
\hline$\alpha(-)$ & $5.52 \times 10^{-1}$ \\
$\beta\left(\mathrm{d}^{-1}\right)$ & $8.23 \times 10^{-4}$ \\
$\gamma\left(\mathrm{d}^{-1}\right)$ & $5.58 \times 10^{-3}$ \\
$d($ day $)$ & 20 \\
\hline
\end{tabular}

\section{(Profit model I)}

First, we introduced profit model $Y_{\mathrm{I}}\left(t, w^{*}, \lambda\right.$ ) (profit model I) when all plants are shipped as low price $s_{l}$ as follows:

$$
Y_{\mathrm{I}}\left(t, w^{*}, \lambda\right)=\left\{\lambda \frac{\mu(t)}{w^{*}}-[\alpha+d \beta+(t-d) \gamma]\right\} n S
$$

In order for the profit to become positive, it is required that $\lambda>\lambda^{*}$ (Fig. 3b). $\lambda^{*}$ is described using a best harvest time $t^{*}$ as follows:

$$
\lambda^{*}\left(t^{*}, w^{*}\right)=\frac{w^{*}}{\mu\left(t^{*}\right)}\left[\alpha+d \beta+\left(t^{*}-d\right) \gamma\right]
$$

(Profit model II)

Next, we introduced profit model $Y_{\text {II }}\left(t, w^{*}\right)$ (profit model II) when larger plants over $w^{*}$ are shipped as standard price $s_{s}$ and other smaller plants under $w^{*}$ are not shipped. The model is described by:

$$
Y_{\mathrm{II}}\left(t, w^{*}\right)=\left\{r^{*}-[\alpha+d \beta+(t-d) \gamma]\right\} n S
$$

When the distribution of fresh weight is described as Gaussian distributions as shown in Fig. 1, yield $r^{*}(-)$ is defined as the ratio of plants above shipping threshold as follows:

$$
r^{*}=\frac{1}{\sqrt{2 \pi} \sigma(t)} \int_{w^{*}}^{\infty} \exp \left[-\frac{(w-\mu(t))^{2}}{2 \sigma(t)^{2}}\right] d w
$$

(Profit model III)

Finally, we introduced profit model $Y_{\mathrm{III}}\left(t, w^{*}, \lambda\right)$ (profit model III) when larger plants over $w^{*}$ are shipped as standard price $s_{s}$ and other smaller plants under $w^{*}$ are shipped as low price $s_{l}$, as follows:

$$
\begin{aligned}
Y_{\mathrm{III}}\left(t, w^{*}, \lambda\right)= & \left\{r^{*}+\left(1-r^{*}\right) \times \lambda \frac{\langle w\rangle}{w^{*}}\right. \\
& -[\alpha+d \beta+(t-d) \gamma]\} n S
\end{aligned}
$$

$\langle w\rangle$ is the average of fresh weight of smaller plants under the threshold $w^{*},\langle w\rangle$ is described by:

$$
\langle w\rangle=\frac{\int_{-\infty}^{w^{*}} w \exp \left[-\frac{(w-\mu(t))^{2}}{2 \sigma(t)^{2}}\right] d w}{\int_{-\infty}^{w^{*}} \exp \left[-\frac{(w-\mu(t))^{2}}{2 \sigma(t)^{2}}\right] d w}
$$

In this study, we used representative values for $t, w^{*}$ and $\lambda$ (40 d, $75 \mathrm{~g}$ and 0.30 , respectively).

\section{Experimental methods}

Experiments were carried out using lettuce (Lactuca sativa L. cv. SB555GL, fixed lines of lettuce cultivars from Snow Brand Seed Co., Ltd., Sapporo, Japan) in a closed-type plant factory in Osaka Prefecture University. 


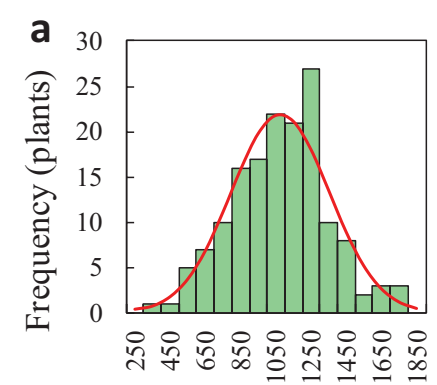

Leaf area $\left(\mathrm{mm}^{2}\right)$

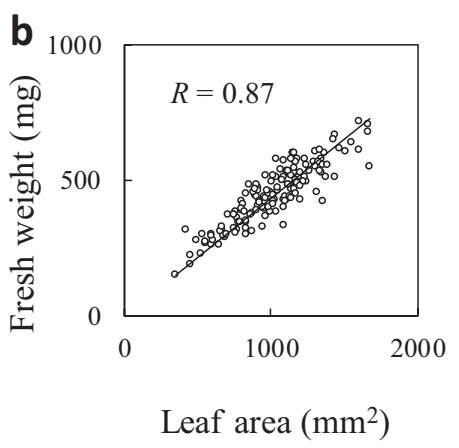

Fig. 1 Gaussian distributions of seedling size. a) Histogram of plant size obtained by calculation of projected leaf area for 153 lettuce seedlings at $17 \mathrm{~d}$ after sowing. Red line shows a function based on probability distribution at Gaussian distributions. b) Relationship between leaf area and fresh weight removing sponge and roots of 153 lettuce seedlings at $17 \mathrm{~d}$ after sowing.
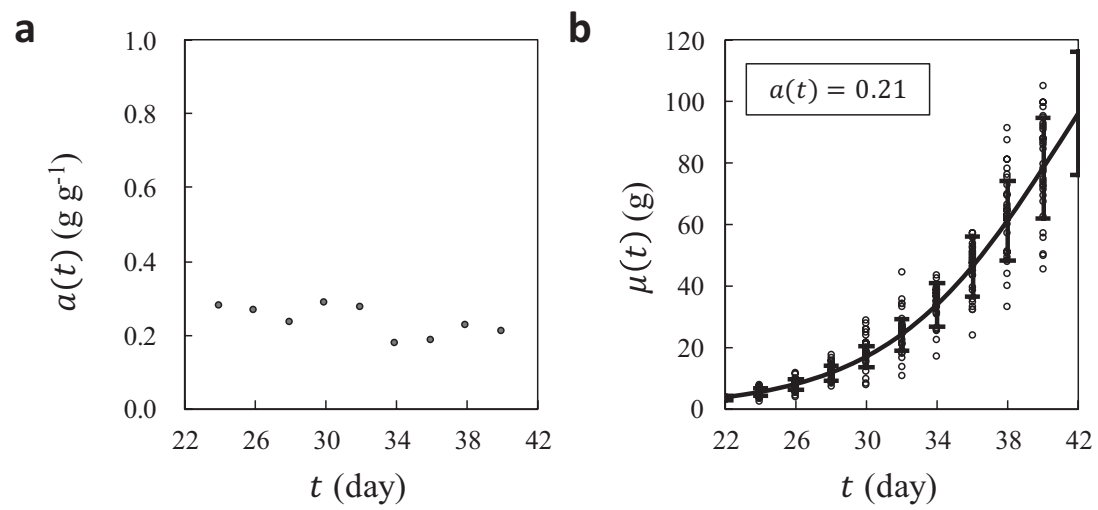

Fig. 2 Growth dynamics of lettuce population. a) Relationship between coefficient of variance $a(t)$ and day after sowing $t$. b) Time variation of average and standard deviation of fresh weight. Black circle plots fresh weight for each plant of experimental data, line is calculation data of fresh weight $\mu(t)$ using Eq. (2), and error bars were calculated using standard deviation $\sigma(t)$.

In this experiment, individual plants are cultivated for 40 d. Firstly, each plant was seeded in a greening panel $(600$ $\mathrm{mm}[\mathrm{W}] \times 600 \mathrm{~mm}[\mathrm{D}])$ allowing 600 plants to be seeded to a urethane sponge sheet (each sponge was $25 \mathrm{~mm}$ $[\mathrm{W}] \times 25 \mathrm{~mm}[\mathrm{D}])$ with $5 \mathrm{~L}$ tap water and fertilizer $\left(\mathrm{N}: \mathrm{P}_{2} \mathrm{O}_{5}: \mathrm{K}_{2} \mathrm{O}: \mathrm{CaO}: \mathrm{MgO}=10: 8: 27: 0: 4\right.$ and $\mathrm{N}: \mathrm{P}_{2} \mathrm{O}_{5}: \mathrm{K}_{2} \mathrm{O}$ : $\mathrm{CaO}: \mathrm{MgO}=11: 0: 0: 23: 0$, Otsuka House No. 1 and 2, respectively; Otsuka Chemical Co., Ltd., Osaka, Japan) at pH 6.0 and electric conductivity (EC) $0.06 \mathrm{~S} \mathrm{~m}^{-1}$. Secondly, the greening panel was laid in the dark at $25^{\circ} \mathrm{C}$ for 2 $\mathrm{d}$ in a growth chamber for germination. Thirdly, plants were cultivated $8 \mathrm{~d}$ under white LED light (LIFELED'S; NEC Lighting, Ltd., Tokyo, Japan) and fluorescent light under 15-h light:9-h dark conditions. Fourthly, plants were cultivated $12 \mathrm{~d}$ under LED light (blue, white, red, and farred LEDs, GreenPower LED production module DR/W/FR 120, Philips, Amsterdam, Netherlands) and 15-h light:9-h dark conditions at $\mathrm{pH} 6.0, \mathrm{EC} 0.12 \mathrm{~S} \mathrm{~m}^{-1}$ and $23.7 \pm 3.0^{\circ} \mathrm{C}$ in nursing room. Finally, plants were cultivated in cultivating room for $18 \mathrm{~d}$ under LED light condition $(190 \mu \mathrm{mol}$ $\mathrm{m}^{-2} \mathrm{~s}^{-1}$ and 15-h light: 9-h dark) using the same LED as the nursing room. We measured the fresh weight of aerial parts for 30 plants at the time from $24 \mathrm{~d}$ to $40 \mathrm{~d}$ after sowing daily.

\section{RESULTS AND DISCUSSION}

Parameters of growth dynamics in lettuce population

We calculated the growth-related parameters, such as $\mu_{\max }, K, t_{o}$ and $a(t)$, from experimental data. Figure $2 \mathrm{a}$ shows the coefficient of variance $a(t)$ using the average $\mu(t)$ and the standard deviation $\sigma(t)$ of the fresh weight at each time. $a(t)$ was almost the same throughout cultivation, although there were some fluctuations, as shown in Fig. 2a. Figure $2 b$ shows the time variation of fresh weight in experimental data and that in simulation data. Black circle plots show fresh weights for each plant of experimental data, lines are calculated data for fresh weight $\mu(t)$ using growth model Eq. (2), and error bars are calculated as standard deviation $\sigma(t)$. In this study, experimental data was well described by the growth model Eq. (2). Representative parameters of Eq. (2) are shown in Table 2.

\section{Profit model of plant factory}

Figure $3 \mathrm{a}$ and $3 \mathrm{~b}$ show the results of profit model I in which all plants are shipped as low price $s_{l}$. In the standard case $w^{*}=75(\mathrm{~g})$, the break-even point is shown as the black line in Fig. $3 a$ and $3 b$. It was found that increases both $t$ and $\lambda$ parameters tend to increase profit. In the typical case $t=40$ (day) and $\lambda=0.30$ in model I, the profit is negative. In order to become profit positive, it is necessary for $\lambda>\lambda^{*}$. In this case, $\lambda^{*}=0.34$ at $t^{*}=58 \mathrm{~d}$. 
Table 2 Representative values for growth-related parameters in Eq. (2) and (3) obtained by GRG method. Growth-related parameters $\left(t_{o}, \mu_{\max }, K\right)$ is the coefficient value of average of fresh weight in Eq. (2) and $a$ is the coefficient of variation in Eq. (3).

\begin{tabular}{cc}
\hline Parameter & Value \\
\hline$t_{o}$ (day) & 41.21 \\
$\mu_{\max }(g)$ & 178.01 \\
$K\left(g^{-1} \mathrm{~d}^{-1}\right)$ & $1.13 \times 10^{-3}$ \\
$a\left(g g^{-1}\right)$ & 0.21 \\
\hline
\end{tabular}

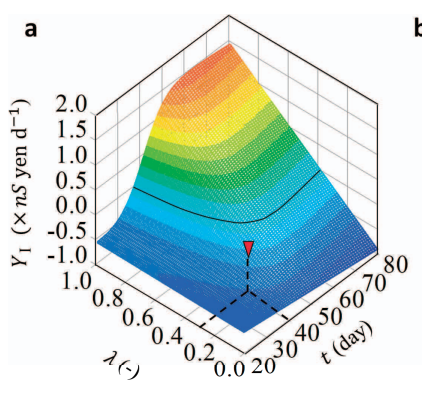

b
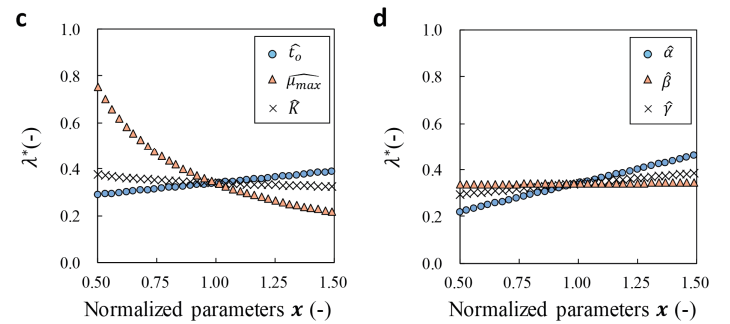

Fig. 3 Profit model I, in which all plants are shipped and sold as low price $s_{l}$. $(\mathrm{a}, \mathrm{b})$ Dependence of profit $Y_{\mathrm{I}}$ on category-weighting factor $\lambda$ and total cultivation time $t$. Color indicates value of $Y_{\mathrm{I}}$. (c, d) Relationship between the critical value of category-weighting factor $\lambda^{*}$ and parameters $\boldsymbol{x}$ (c: growth-related, d: cost-related). Parameter $\boldsymbol{x}$ is normalized against the representative value, as shown in Tables 1 and 2 . In this figure, $w^{*}=$ $75 \mathrm{~g}$. Red triangle indicates a typical case.

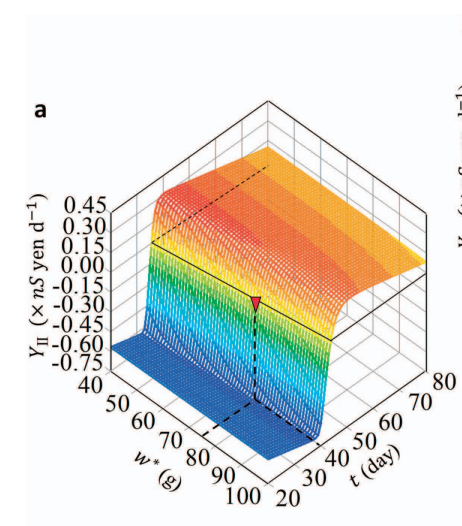

b

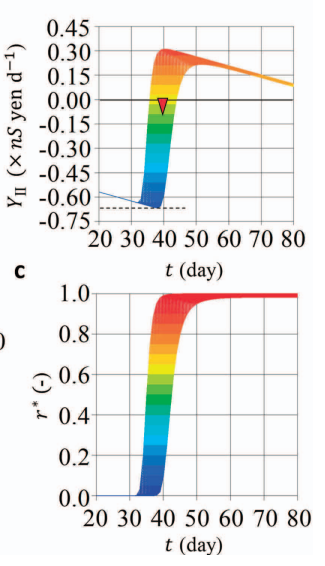

Fig. 4 Profit model II, in which larger plants over $w^{*}$ are shipped as standard price $s_{s}$ and other smaller plants under $w^{*}$ are not shipped. (a) Dependence of profit $Y_{\text {II }}$ on shipping threshold $w^{*}$ and total cultivation time $t$. (b) Relationship between profit $Y_{\text {II }}$ and total cultivation time $t$. (c) Relationship between yield $r^{*}$ and total cultivation time $t$. Color indicates value of $Y_{\mathrm{II}}$. Red triangle indicates a typical case.

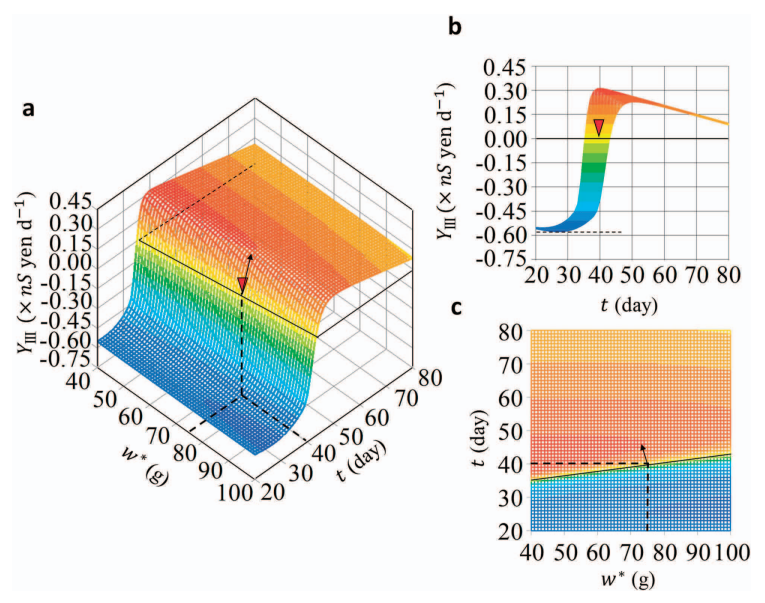

Fig. 5 Profit model III, in which larger plants over $w^{*}$ are shipped as standard price $s_{s}$ and smaller plants under $w^{*}$ are shipped as low price $s_{l}$. (a) Dependence of profit $Y_{\text {III }}$ on shipping threshold $w^{*}$ and total cultivation time $t$. (b) Relationship between profit $Y_{\mathrm{III}}$ and total cultivation time $t$. (c) Top view of Fig. 5a. Color indicates the value of $Y_{\text {III }}$. Red triangle indicates typical case.
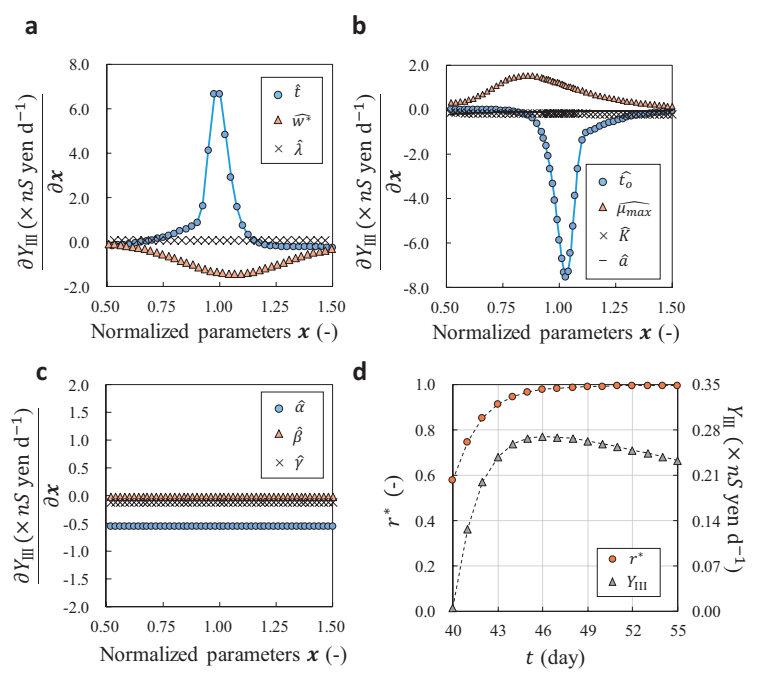

Fig. 6 Sensitivity analysis of parameters on profit $\partial Y_{\mathrm{III}} / \partial \boldsymbol{x}$ (a: selling-related, b: growth-related, c: cost-related). (d) Relationship between yield $r^{*}$ and total cultivation time $t$ with $w^{*}=75 \mathrm{~g}, \lambda=0.30$. Parameters $\boldsymbol{x}$ are normalized against representative values, as shown in Tables 1 and 2 .

Next, Fig. 4 show profit model II in when larger plants over $w^{*}$ are shipped at standard price $s_{s}$ and other smaller plants under $w^{*}$ are not shipped. This model does not depend on $\lambda$. In a typical case $\left(t=40 \mathrm{~d}\right.$ and $w^{*}=75$ $\mathrm{g}$ ), the profit $Y_{\mathrm{II}}$ is negative. Figure $4 \mathrm{~b}$ shows the dependence of $Y_{\mathrm{II}}$ on $t$. Before the 35 th $\mathrm{d}$ the profit decreases over time, because the yield $r^{*}$, the ratio of plants that are over $w^{*}$, is almost zero and the running costs increase over time. Profit increases markedly at about the 35th d, because plant growth is accelerated according to logistic function (Eq. 2) and then yield $r^{*}$ increases sharply. After the 45th d, yield $r^{*}$ reaches almost $100 \%$ (Fig. 4c). On the other hand, costs increase over time continuously and profit $Y_{\text {II }}$ decreases over time (Fig. 4b). Thus, the profit is strongly 
GROWTH AND SHIPPING TYPE

Table 3 Analytical range of variables and parameters.

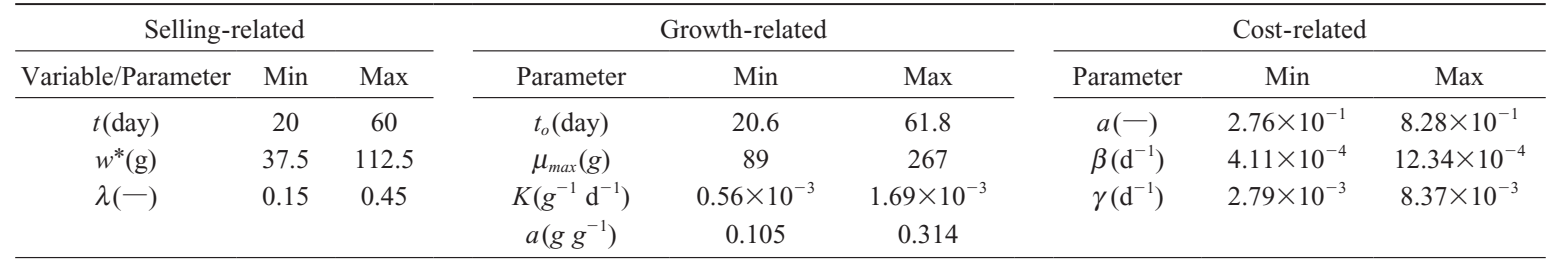

affected by growth-related parameters. Therefore, identification of growth-related parameters is one an important task for considering the profits of plant factories.

Figure 5 shows the simulation results for profit model III, when plants above shipping threshold are sold at a standard price $s_{s}$ and those at less than this threshold are sold at a low price $s_{l}$. In this shipping type, a typical case ( $t=$ $40 \mathrm{~d}, w^{*}=75 \mathrm{~g}$ and $\lambda=0.30$ ) provides a positive profit. Thus, addition of shipping by unit of fresh weight (yen $\mathrm{g}^{-1}$ ) improves profits. The minimum value of profit $(-0.58$ as shown in a dashed line of Fig. $5 b)$ is improved as compared with profit model II $(-0.68$ as shown in a dashed line of Fig. 4b). In Fig. 5a and 5c, the arrow indicates the most effective direction of profit improvement by parameter optimization. In addition, it is preferable that yield $r^{*}$ is not close to $100 \%$, but closer to $95 \%$ in Fig. $6 \mathrm{~d}$.

Sensitivity analysis of parameters of profit model

In order to maximize profit at a plant factory, it is necessary to optimize all the parameters in the model. In particular, based on the results of parameter sensitivity analysis, it is necessary to optimize in order from high priority parameters. However, precise information on the parameters are determined after reaching steady operation at plant factory, so that it is necessary to give an adjustment range to the parameters. Therefore, in order to maximize profit, 1) optimization of prior parameters and 2) design of the adjustment range are important. Therefore, in this study, prior parameters were identified by sensitivity analysis, and parameter adjustment was investigated.

Figures $3 \mathrm{c}$ and $3 \mathrm{~d}$ show the parameter sensitivity for profit model I in which all plants are shipped as low price $s_{l}$. Here, $\hat{x}$ is normalized against the representative value in each parameter $x$. In this profit model, we focused on $\lambda^{*}$, which is a key factor of the break-even point. We analyzed how this $\lambda^{*}$ changes when other parameters vary. Figures $3 \mathrm{c}$ and $3 \mathrm{~d}$ show the change in $\lambda^{*}$ referring to the growth-related parameters $\left(t_{o}, \mu_{\max }, K\right)$ and cost-related parameters $(\alpha, \beta, \gamma)$. The horizontal axis is the amount of change in each parameter from the representative values (Tables 1 and 2), and the range of change is shown in Table 3. As mentioned above, the smaller $\lambda^{*}$ provides a wider parameter region in which profit arises, so that the value of $\lambda^{*}$ is important for improvement of profit. In the parameters of profit model I, $\mu_{\max }$ shows largest sensitivity ( $\lambda^{*}$ changes from 0.22 to 0.75$)$ among the three growth-related parameters $\left(t_{o}, \mu_{\max }, K\right)$. This indicates that a plant showing a larger fresh weight at the harvesting stage is the most important factor for selection of lettuce variety. In addition, $\alpha$ is the most sensitive for $\lambda^{*}$ among the three cost-related parameters $(\alpha, \beta, \gamma)$, indicating that it is important to re- duce the fixed costs $(\alpha)$ rather than the running costs $(\beta$, $\gamma)$.

We analyzed the amount of $\partial Y_{\text {III }} / \partial \boldsymbol{x}$, which shows the sensitivity of parameter $\boldsymbol{x}$ to the profit $Y_{\mathrm{III}}$ in profit model III, as shown in Fig. 6. Figure 6a shows the $\partial Y_{\text {III }} / \partial \boldsymbol{x}$ for the selling-related parameters $\left(t, w^{*}, \lambda\right) . \partial Y_{\mathrm{III}} / \partial t$ shows a large positive value (maximally 6.7) around the representative value $(\hat{t}=1.00)$. This indicates that, for example, if $\hat{t}$ increases from 1.00 to $1.01, Y_{\text {III }}$ increases an amount of about $0.067 \times n S$ (yen $\mathrm{d}^{-1}$ ); in contrast, if $\hat{t}$ decreases from 1.00 to $0.99, Y_{\text {III }}$ changes about $-0.067 \times n S\left(\right.$ yen $\left.\mathrm{d}^{-1}\right) . \partial Y_{\mathrm{III}} / \partial w^{*}$ shows negative value (minimally -1.4$)$ around the representative value $\left(\widehat{w}^{*}=1.00\right)$, indicating that $Y_{\mathrm{III}}$ decreases if $w^{*}$ increases. $\partial Y_{\mathrm{III}} / \partial \lambda$ shows almost zero, indicating that $\lambda$

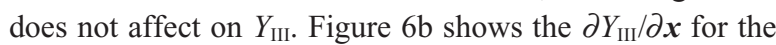
growth-related parameters $\left(t_{o}, \mu_{\max }, K, a(t)\right) . \partial Y_{\mathrm{III}} / \partial t_{o}$ and $\partial Y_{\text {III }} / \partial \mu_{\max }$ show negative and positive values, respectively. In particular, $\partial Y_{\text {III }} / \partial t_{o}$ shows a large negative value (minimally -7.8), indicating that if $t_{o}$ increases, $Y_{\text {III }}$ decreases drastically. This suggests that only slightly worse conditions for seedlings lead to a large loss in profit. Figure $6 \mathrm{c}$ shows $\partial Y_{\mathrm{III}} / \partial \boldsymbol{x}$ for the cost-related parameters $(\alpha, \beta, \gamma)$. Because $\partial Y_{\text {III }} / \partial \alpha$ shows a constant value $(-0.55), Y_{\text {III }}$ decreases in proportion to $\alpha$. From the above, seedling size $t_{o}$ and total cultivation time, shipping threshold $w^{*}$, and maximum value at time infinite $\mu_{\max }$ are high priority parameters to be optimized. In addition, $Y_{\mathrm{III}}$ is maximum at yield $r^{*}=0.95$, suggesting that $100 \%$ yield is not optimal (Fig. 6c).

From the sensitivity analysis of each parameter, it was clarified that the quality of seedling and cultivation days are mostly effective to ensure profit. In contrast, cost-related parameters do not show any specific sensitivity. However, because equipment for controlling growth is included as fixed costs, it is necessary to pay attention to the tradeoff relationship between growth-related and fixed cost-related parameters.

\section{CONCLUSION}

In this study, we established three profit models based on shipping type and growth dynamics at each growth stage (nursing stage and cultivating stage). Profit model I is in when all plants are shipped as low price; profit model II is in when larger plants over the shipping threshold are shipped as standard price and smaller plants under the threshold are not shipped; profit model III is in when larger plants over the shipping threshold are shipped as standard price and smaller plants under the shipping threshold are shipped as low price. From the sensitivity analysis of each 


\section{S. MORIYUKI ET AL.}

parameter, it was clarified that seedling size at planting in the nursery room and total cultivation days have the greatest effect on profit. In contrast, cost-related parameters do not show any specific sensitivity. In the future, in order to become a widespread technology in plant factories, it is necessary to comprehensively link various fields such as growth dynamics, profit models, and environmental control systems.

\section{ACKNOWLEDGEMENTS}

We are grateful to Osaka Sakai Plant Factory Co. for cultivation. This study was supported by a Ministry of Education, Science, Sports and Culture, Grant-in-Aid for Scientific Research (No. 25712029 to H. F.) and Precursory Research for Embryonic Science and Technology (no. JPMJPR15O4) of the Japan Science and Technology Agency (to H.F.).

\section{REFERENCES}

Gabriele, G. A., Ragsdell, K. M. 1977. The generalized reduced gradient method: A reliable tool for optimal design. J. Eng. Ind. 99: 394-400.
Ko, M.T., Ahn, T.I., Cho, Y.Y., Son, J.E. 2013. Uptake of nutrients and water by paprika (Capsicum annuum L.) as affected by renewal period of recycled nutrient solution in closed soilless culture. Hort. Environ. Biotechnol. 54: 412-421.

Kozai, T. 2007. Propagation, grafting and transplant production in closed systems with artificial lighting for commercialization in Japan. Propag. Ornam. Plants 7: 145-149.

Kozai, T., Niu, G., Takagaki, M. 2015. Plant factory-An indoor vertical farming system for efficient quality food production-. Academic Press, Cambridge, Massachusetts.

Moriyuki, S., Fukuda, H. 2016. High-throughput growth prediction for Lactuca sativa L. seedlings using chlorophyll fluorescence in a plant factory with artificial lighting. Front. Plant Sci. 7: 394.

Ohyama, K. 2015. Actual management conditions on a largescale plant factory with artificial lighting. JGHA Prit. Hortic. 168: $30-33$.

Shuku, T., Nishimura, S. 2015. Sensitivity analysis in stability evaluation of earthen embankments. Jpn. Geotechnical Soc. Special Publ. 49: 1723-1726.

Son, J.E., Takakura, T. 1987. A study on automatic control of nutrient solutions in hydroponics. J. Agric. Met. 43: 147-151.

Soran, V., Lazar-Keul, G. 1978. Relationship between cell growth and rate of protoplasmic streaming. Cytologia 43: 265271. 